\title{
TNF- $\alpha$ induces Drp1-mediated mitochondrial fragmentation during inflammatory cardiomyocyte injury
}

\author{
YUE-LIANG SHEN ${ }^{1}$, YING-ZHOU SHI ${ }^{1}$, GAI-GE CHEN ${ }^{1}$, LIN-LIN WANG $^{2}$, \\ MING-ZHI ZHENG ${ }^{3}$, HONG-FENG JIN ${ }^{4}$ and YING-YING CHEN ${ }^{1}$ \\ ${ }^{1}$ Department of Pathology and Pathophysiology and ${ }^{2}$ Center for Stem Cell and Tissue Engineering, \\ Zhejiang University School of Medicine, Hangzhou, Zhejiang 310058; \\ ${ }^{3}$ Department of Pharmacology, Hangzhou Medical College, Hangzhou, Zhejiang 310053; \\ ${ }^{4}$ Department of Cardiology, Zhejiang Hospital, Hangzhou, Zhejiang 310013, P.R. China
}

Received July 18, 2017; Accepted January 9, 2018

DOI: $10.3892 /$ ijmm.2018.3385

\begin{abstract}
Dynamin-related peptide 1 (Drpl)-mediated mitochondrial fission is an important process associated with cardiac dysfunction under different pathological conditions. The aim of the present study was to investigate the expression of Drpl during inflammatory myocardial injury. Sprague-Dawley rats were treated intraperitoneally with lipopolysaccharides (LPS). Furthermore, cultured H9C2 cardiomyocytes were treated with LPS, interleukin-6 (IL-6) and tumor necrosis factor- $\alpha$ (TNF- $\alpha)$. Total and mitochondrial proteins were isolated from the heart tissue of rats and from the H9C2 cardiomyocytes. Expression levels of Drp1 and RhoA were analyzed by western blotting. Mitochondrial morphology was determined using confocal laser microscopy. The levels of mitochondrial Drp1 and phosphorylated-Drp1 (p-Drp1) Ser616 were revealed to be increased in rats $6 \mathrm{~h}$ after injection with LPS $(5,10$ or $20 \mathrm{mg} / \mathrm{kg})$. Furthermore, treatment with LPS and IL-6 did not demonstrate a significant effect on the expression of total and mitochondrial Drp1 in H9C2 cardiomyocytes in vitro; however, treatment with TNF- $\alpha$ (20 ng/ml) significantly enhanced the levels of mitochondrial Drp1 and p-Drp1 Ser616. Following TNF- $\alpha$ treatment, the expression of Ras homolog gene family member A (RhoA) was also revealed to increase. Treatment with both Y-27632 and fasudil, [Rho kinase (ROCK) inhibitors], was demonstrated to attenuate the otherwise TNF- $\alpha$-induced increase
\end{abstract}

Correspondence to: Dr Hong-Feng Jin, Department of Cardiology, Zhejiang Hospital, 12 Lingying Road, Hangzhou, Zhejiang 310013, P.R. China

E-mail: jinhf96@163.com

Dr Ying-Ying Chen, Department of Pathology and Pathophysiology, Zhejiang University School of Medicine, 866 Yuhangtang Road, Hangzhou, Zhejiang 310058, P.R. China

E-mail: bchenyy@zju.edu.cn

Key words: tumor necrosis factor- $\alpha$, dynamin-related peptide 1, mitochondrial fragmentation, Ras homolog gene family member A, Rho kinase in p-Drp1 Ser616 and mitochondrial Drp1. In addition, it was revealed that Y-27632 and fasudil may also attenuate the TNF- $\alpha$-induced increase in mitochondrial fragmentation and cell viability. Therefore, the findings of the present study suggest that TNF- $\alpha$ is the predominant inducer of Drp1 S616 phosphorylation during sepsis. The results of the present study also suggest that the RhoA/ROCK pathway may be involved in the phosphorylation and mitochondrial translocation of Drp1, which leads to mitochondrial fragmentation.

\section{Introduction}

Cardiomyocytes are enriched in mitochondria, which are considered to have a stable, elongated shape. Previous studies have revealed that mitochondrial morphology in cardiomyocytes alternates between elongated interconnected mitochondrial networks and a fragmented disconnected arrangement $(1,2)$. The dynamic balance of mitochondrial fusion and fission is involved in the regulation of numerous cellular functions, such as apoptosis, autophagy, metabolism and contractility $(3,4)$.

Dynamin-related peptide 1 (Drpl), a member of the dynamin GTPase superfamily, has an important role in the process of mitochondrial fission (5). Ong et al demonstrated that inhibition of mitochondrial fission in HL-1 cells (a cardiac-derived cell line), via transfection with a dominant negative mutant form of Drp1 (K38A), may reduce ischemia/reperfusion-induced cell death (6). Furthermore, Drp1-mediated mitochondrial fission has also been demonstrated to be correlated with increased autophagy in adult cardiomyocytes (7). In addition, second mitochondria-derived activator of caspase (Smac)/direct IAP-binding protein with low pI (DIABLO) is necessary for hydrogen oxide-induced apoptosis in neonatal rat cardiomyocytes and a subsequent release of Smac/DIABLO from the mitochondria into the cytosol occurs as a consequence of mitochondrial fission regulated by Drp1 (8). Drp1-mediated mitochondrial fission is thus considered to be an important inducer of cardiac dysfunction under different pathological conditions.

Expression of inflammatory cytokines, such as interleukin-6 (IL-6) and tumor necrosis factor- $\alpha$ (TNF- $\alpha$ ) are 
enhanced in patients with heart failure, atrial fibrillation and myocardial infarction (9-11). Pharmacological inhibition of Drp1 prevents mitochondrial fission in TNF- $\alpha$-treated cells (12). In the lipopolysaccharide (LPS)-induced sepsis mice model, Drp1-mediated mitochondrial dysfunction has an important role in the suppression of cardiac contractility and bioenergetic functioning (13). In addition, Gonzalez et al (14) revealed that expression of Drp1 mRNA is enhanced in cecal ligation and puncture sepsis models, but not in LPS-induced endotoxemia models. Whether the process of mitochondrial fission is directly induced by LPS, or indirectly induced via inflammatory cytokines, remains undermined.

The present study aimed to investigate the Drp1 expression during inflammatory myocardial injury.

\section{Materials and methods}

Reagents. LPS (from Escherichia coli 055:B5), TNF- $\alpha$, IL-6, KN-93 and $\beta$-actin antibody (cat no. A5316) were purchased from Sigma-Aldrich; Merck KGaA (Darmstadt, Germany). Y-27632 and fasudil were obtained from Selleck Chemicals (Houston, TX, USA). Antibodies against: Drp1 (cat no. 8570), phosphorylated Drp1 (p-Drp1) Ser616 (cat no. 4494), p-Drp1 Ser637 (cat no. 4867), calcium/calmodulin-dependent protein kinase type II (CaMK II) (cat no. 4436), phosphorylated c-Jun N-terminal kinase (p-JNK) (cat no. 4668), Ras homolog gene family member A (RhoA) (cat no. 2117), Ras-related $\mathrm{C} 3$ botulinum toxin substrate 1 ( Rac1)/cell division control protein 42 homolog (Cdc42) (cat no. 4651) and voltage dependent anion channel (VDAC, cat no. 4866) were purchased from Cell Signaling Technology, Inc. (Danvers, MA, USA). The LPS ELISA kit (cat no. CSB-E14247r) was purchased from Cusabio Biotech Co., Ltd. (Wuhan, Hubei, China) and the TNF- $\alpha$ and IL-6 ELISA kits (cat nos. BMS622 and BMS625, respectively) were purchased from eBioscience; Thermo Fisher Scientific, Inc. (Waltham, MA, USA). Cell Counting Kit-8 (CCK-8) was purchased from Dojindo Molecular Technologies, Inc. (Kumamoto, Japan). MitoTracker TM Red CMXRos was purchased from Thermo Fisher Scientific, Inc.

Animals. A total of 32 male Sprague-Dawley rats (230-250 g, 7-8 weeks old) were purchased from the Experimental Animal Center of Zhejiang University (Hangzhou, China) and cared for in compliance with the Guide for the Care and Use of Laboratory Animals (National Institutes of Health, Bethesda, MD, USA). Four rats per cage were housed in a controlled room $\left(20-24^{\circ} \mathrm{C}, 40-60 \%\right.$ humidity) and 12/12-h light/dark cycle. All rats were allowed free access to water and food. The rats were randomly divided into 4 groups ( $\mathrm{n}=8$ each), and injected intraperitoneally with either $0.9 \% \mathrm{NaCl}$ (for control group) or LPS $(5,10$ or $20 \mathrm{mg} / \mathrm{kg}$ in $0.9 \% \mathrm{NaCl})$ in order to establish the sepsis model as previously described (15). All experimental protocols were approved by the Ethics Committee on Animal Experimentation of Zhejiang University (Hangzhou, China).

Cell treatment. H9C2 rat cardiomyocyte cell line was purchased from the Chinese Academy of Sciences (Shanghai, China). Cells were incubated in completed Dulbecco's modified Eagle's medium (DMEM; Genom Biomedical Technology
Corporation, Hangzhou, China) containing $10 \%$ fetal bovine serum (Sijiqing Corporation, Hangzhou, China) in a humidified $5 \% \mathrm{CO}_{2}$ environment. Following further incubation with serum-free medium for $12 \mathrm{~h}$ at $37^{\circ} \mathrm{C}$, cells were divided into the following groups: i) Control group, untreated cells; ii) LPS groups, cells were treated with $0.01,0.1$ or $1 \mu \mathrm{g} / \mathrm{ml} \mathrm{LPS}$; iii) TNF- $\alpha$ groups, cells were treated with 5,10 or $20 \mathrm{ng} / \mathrm{ml}$ TNF- $\alpha$; iv) IL- 6 groups, cells were treated with 5,10 or $20 \mathrm{ng} / \mathrm{ml}$ IL-6; v) TNF- $\alpha+\mathrm{KN}-93$ group, cells were incubated with a CaMK II inhibitor, $1 \mu \mathrm{M} \mathrm{KN}-93$, for $1 \mathrm{~h}$ at $37^{\circ} \mathrm{C}$, and then co-incubated with $20 \mathrm{ng} / \mathrm{ml} \mathrm{TNF}-\alpha$ for 6 or $48 \mathrm{~h}$ at $37^{\circ} \mathrm{C}$; vi) TNF- $\alpha+Y-27632 /$ fasudil group, cells were incubated with Rho kinase (ROCK) inhibitors $1 \mu \mathrm{M}$ Y-27632 orl $\mu \mathrm{M}$ fasudil for $1 \mathrm{~h}$ at $37^{\circ} \mathrm{C}$, and then co-incubated with $20 \mathrm{ng} / \mathrm{ml} \mathrm{TNF-} \alpha$ for 6 or $48 \mathrm{~h}$ at $37^{\circ} \mathrm{C}$; and vii) $\mathrm{KN}-93 / \mathrm{Y}-27632 /$ fasudil alone group, cells were incubated with $1 \mu \mathrm{M} \mathrm{KN}-93,1 \mu \mathrm{M}$ Y-27632 or $1 \mu \mathrm{M}$ fasudil for 7 or $49 \mathrm{~h}$ at $37^{\circ} \mathrm{C}$. Protein levels were determined $6 \mathrm{~h}$ post-treatment of TNF- $\alpha$, and cellular viability was evaluated $48 \mathrm{~h}$ post-treatment of TNF- $\alpha$.

Determination of cytokine concentration in rat serum. Rat blood samples were collected in clot activator-coated test tubes. Serum was extracted via centrifugation at $1,000 \mathrm{x} \mathrm{g}$ for $10 \mathrm{~min}$ at room temperature and then stored at $-80^{\circ} \mathrm{C}$ until analysis. Subsequently, the serum LPS levels were determined using ELISA kits in accordance with the manufacturer's protocol (Cusabio Biotech Co., Ltd.). Plasma TNF- $\alpha$ and IL-6 levels were determined using ELISA kits in accordance with the manufacturer's protocol (eBioscience; Thermo Fisher Scientific, Inc.).

Cell viability assay. H9C2 cells were seeded into 96-well plates (1,000 cells/well). Cells were washed and supplemented with serum-free DMEM medium $48 \mathrm{~h}$ after the aforementioned treatments. CCK- 8 solution was then added to the culture medium at a dilution of $1: 10$ for $2 \mathrm{~h}$ at $37^{\circ} \mathrm{C}$. A highly water-soluble tetrazolium salt, WST- 8 , which is utilized in CCK-8 solution, can receive two electrons from viable cells to generate an orange or purple formazan dye. The quantity of WST-8 formazan dyes, which are directly proportional to the number of living cells, was subsequently analyzed using a microplate reader (Tecan Infinite M200; Tecan Group Ltd., Mannedorf, Switzerland) at a wavelength of $450 \mathrm{~nm}$.

Isolation of cardiac mitochondria. Mitochondria were isolated from rat ventricular myocardium using the Tissue Mitochondria Isolation kit, in accordance with the manufacturer's protocol (eBioscience; Thermo Fisher Scientific, Inc.). Mitochondria in H9C2 cells were isolated using the Mitochondria Isolation Kit for Cultured Cells (Thermo Fisher Scientific, Inc.).

Western blot analysis. Left ventricular myocardium tissue and H9C2 cells were lysed in ice cold cell lysis buffer containing a protease/phosphatase inhibitor cocktail (Cell Signaling Technology, Inc., Danvers, MA, USA). Following centrifugation at $14,000 \times \mathrm{g} 4^{\circ} \mathrm{C}$ for $5 \mathrm{~min}$, the supernatants were collected. The protein concentration in supernatants was determined by using BCA Protein Assay kit (cat. no. P0012; Beyotime Institute of Biotechnology, Haimen, China). Aliquots of total cell extract or mitochondria containing $20 \mu \mathrm{g}$ protein were loaded on a 
$10 \%$ SDS-PAGE gel. The proteins were transferred to nitrocellulose membranes (Invitrogen; Thermo Fisher Scientific, Inc.). Membranes were blocked with $5 \%$ bovine serum albumin (BSA; Shanghai Sangon Biological Engineering Technology $\&$ Services Co., Shanghai, China) for $1 \mathrm{~h}$ at room temperature, membranes were then incubated with primary antibodies $(1: 1,000)$ overnight at $4^{\circ} \mathrm{C}$. Following washing, membranes were incubated with the horseradish peroxidase-conjugated secondary antibody (1:1,000; cat. nos. 7074 and 7076; Cell Signaling Technology, Inc.) for $1 \mathrm{~h}$ at room temperature. An enhanced chemiluminescence kit (Beyotime Institute of Biotechnology) was used for protein visualization. The membranes were then stripped and re-probed using $\beta$-actin and VDAC antibodies, which represent the internal loading controls. The band densities were subsequently determined using Quality One version 4.6.2 (Bio-Rad Laboratories, Inc., Hercules, CA, USA) and normalized to $\beta$-actin or VDAC. Experiments were performed in triplicate.

Immunofluorescence analysis of p-DRP1 Ser616. Cells were cultured on coverslips and then fixed with PBS containing $4 \%$ paraformaldehyde for $15 \mathrm{~min}$ at room temperature. Furthermore, cells were blocked with $1 \%$ BSA in PBS for $30 \mathrm{~min}$ at room temperature, and were then incubated with antibodies against p-Drp1 Ser616 $(1: 2,000)$ overnight at $4^{\circ} \mathrm{C}$. Following thorough washing, the cells were then incubated with Alexa Fluor 488-conjugated anti-rabbit-IgG (1:1,000; cat. no. 4412; Cell Signaling Technology, Inc.) at room temperature for $1 \mathrm{~h}$. Images of fluorescently-labeled cells were obtained using a Confocal Laser Scanning Biological microscope at magnification, x40 (FV3000; Olympus Corporation, Tokyo, Japan). Resulting images were analyzed using Image Pro Plus version 6.0 (Media Cybernetics Inc., Rockville, MD, USA).

Determination of mitochondrial fragmentation in $\mathrm{H} 9 \mathrm{C} 2$ cells. Following aforementioned treatments, cells were incubated with a mitochondria-specific dye $200 \mathrm{nM}$ MitoTracker TM Red CMXRos for $15 \mathrm{~min}$ at $37^{\circ} \mathrm{C}$ in a $5 \%$ $\mathrm{CO}_{2}$ incubator. Following two washes with PBS, cells were exposed to 4',6-diamidino-2-phenylindole (5 $\mu \mathrm{g} / \mathrm{ml})$ for $5 \mathrm{~min}$ in order to stain the nuclei. Cells were then washed twice and suspended in PBS pH 7.4. Images of fluorescently-labeled cells were examined using a Confocal Laser Scanning Biological microscope at magnification, x60 (FV1000; Olympus Corporation). The mitochondrial quantity, individual area of each mitochondria and mitochondrial length-width ratio were quantified according to fission criteria as previously described (16) using Image Pro Plus version 6.0. A decrease in mitochondrial area combined with an increase in the number of mitochondria was considered to represent fission criteria.

Statistical analysis. Data were expressed as mean \pm standard error of the mean and analyzed using either the Student's t-test or one-way analysis of variance followed by Student-Newman-Keuls post hoc test. Prism version 5.0 (GraphPad Software, Inc., La Jolla, CA, USA) was used to analyze the data. $\mathrm{P}<0.05$ was considered to indicate a statistically significant difference.

\section{Results}

LPS increases the level of p-Drp1 Ser616 and mitochondrial translocation in rat heart tissues. Total Drp1 expression in rat heart tissues did not significantly change $6 \mathrm{~h}$ after injection with 5,10 or $20 \mathrm{mg} / \mathrm{kg}$ LPS; however, the expression of mitochondrial Drp1 was revealed to significantly increase in a dose-dependent manner (Fig. 1A-D; P<0.05), suggesting that sepsis may induce mitochondrial translocation of Drp1. Furthermore, the level of p-Drp1 Ser616 significantly increased in the LPS-treated groups compared with the control group (Fig. 1E-G; P<0.05); however, levels of p-Drp1 Ser637 did not significantly change post-treatment with LPS.

LPS increases the concentration of TNF-a and IL-6 in rat serum. Following injection with LPS $(20 \mathrm{mg} / \mathrm{kg})$, the serum level of LPS was revealed to significantly increase $1 \mathrm{~h}$ post-injection, and increase $\sim 4.5$-fold $6 \mathrm{~h}$ post-injection compared with the control (Fig. 2A). Furthermore, LPS administration significantly increased the TNF- $\alpha$ and IL-6 concentration in rat serum samples (Fig. 2B and C). The concentration of serum TNF- $\alpha$ reached high level at $1.5 \mathrm{~h}$ after LPS injection, no significant difference was identified when compared with that of $6 \mathrm{~h}$ post-treatment. The concentration of serum IL- 6 was highest at $6 \mathrm{~h}$ of post-treatment. Treatment with LPS (0.01-1 $\mu \mathrm{g} / \mathrm{ml})$, TNF- $\alpha(10-20 \mathrm{ng} / \mathrm{ml})$ and IL-6 $(10-20 \mathrm{ng} / \mathrm{ml})$ for $48 \mathrm{~h}$ resulted in a significant decrease in the viability of cultured H9C2 cardiomyocytes (Fig. 3). LPS $(1 \mu \mathrm{g} / \mathrm{ml}), 20 \mathrm{IL}-6(\mathrm{ng} / \mathrm{ml})$ and TNF- $\alpha(20 \mathrm{ng} / \mathrm{ml})$ were then used for subsequent experiments.

Treatment with TNF- $\alpha$ increases the level of mitochondrial Drpl in H9C2 cells. H9C2 cells were treated with $1 \mu \mathrm{g} / \mathrm{ml}$ LPS, $20 \mathrm{ng} / \mathrm{ml} \mathrm{IL-6}$ and $20 \mathrm{ng} / \mathrm{ml} \mathrm{TNF}-\alpha$ to investigate the effects of inflammatory cytokines on the expression and mitochondrial translocation of Drp1. Cells were also incubated with serum (1:100) obtained from three rats $1 \mathrm{~h}$ post-LPS injection. Compared with the control group, administration of LPS and IL-6 did not exhibit a significant effect on the expression of total Drp1 and mitochondrial Drp1 (Fig. 4; P>0.05). However, following treatment with TNF- $\alpha(20 \mathrm{ng} / \mathrm{ml})$ and serum from LPS-injected rats, the level of mitochondrial Drp1 increased 2-fold compared with the control; however, total Drp1 expression did not significantly change post-treatment (Fig. 4; $\mathrm{P}<0.01)$.

CaMK II and JNK are not involved in TNF- $\alpha$-induced phosphorylation of Drpl. The mechanism underlying TNF- $\alpha$-induced phosphorylation of Drp1 remains to be elucidated. Incubation of $\mathrm{H} 9 \mathrm{C} 2$ cells with TNF- $\alpha(20 \mathrm{ng} / \mathrm{ml})$ was revealed to significantly enhance the expression of CaMK II compared with control (Fig. 5; P<0.01 vs. control); however, the level of p-JNK did not significantly change following treatment with TNF- $\alpha$ (Fig. 5; P>0.05 vs. control). Furthermore, the level of p-Drp1 Ser616 was significantly increased following treatment with TNF- $\alpha$ (Fig. 6; P<0.01 vs. control). In addition, it was demonstrated that treatment with KN-93, an inhibitor of CaMK II, did not significantly inhibit the TNF- $\alpha$-induced increase in the levels of mitochondrial Drp1 and p-Drp1 Ser616 (Fig. 6A-D; P>0.05 vs. control), nor significantly inhibit 

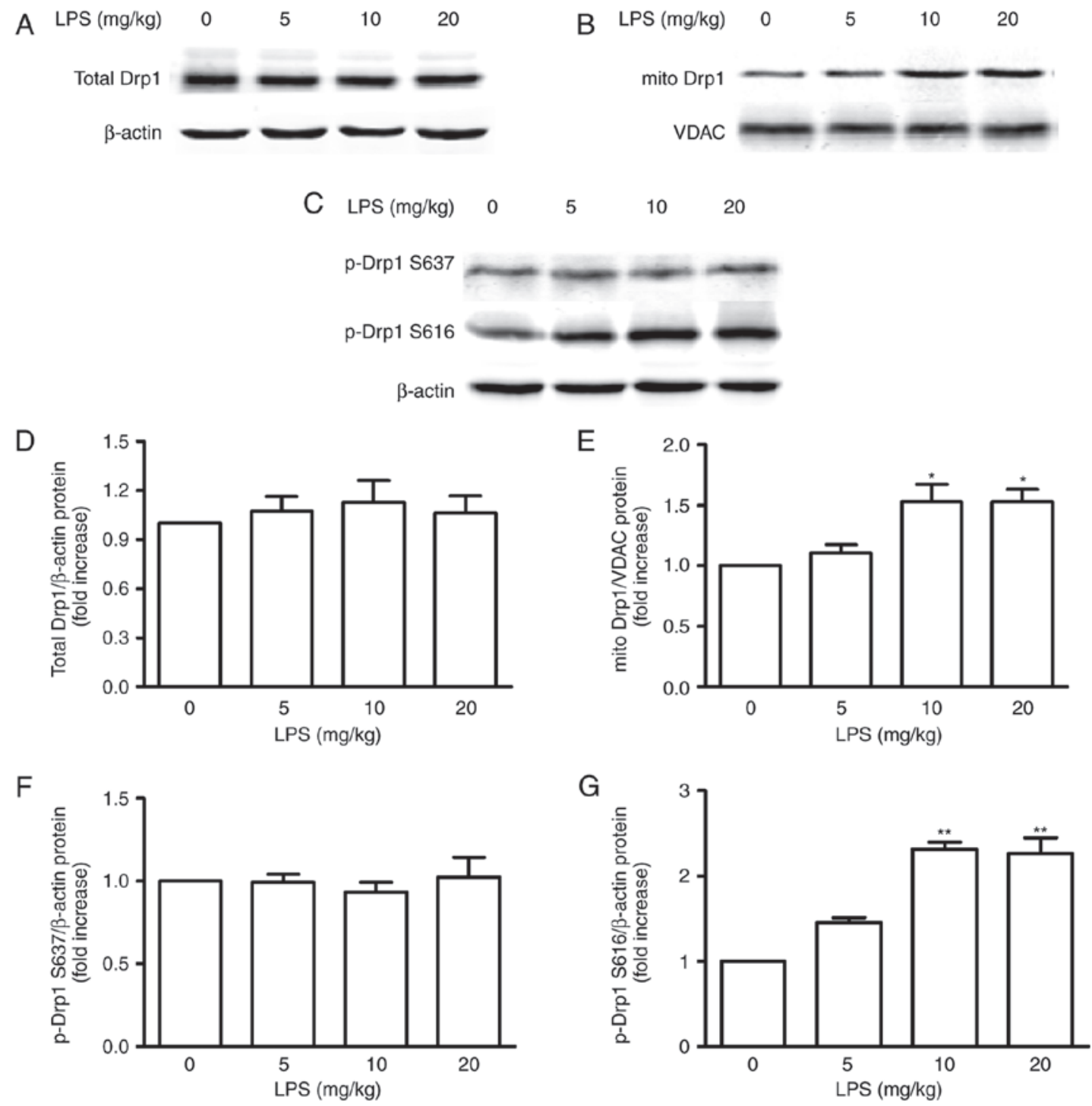

Figure 1. Changes in Drp1 protein expression in rat hearts following injection with LPS. Representative western blot analyses revealed the expression levels of (A) total Drp1, (B) mito Drp1, and (C) p-Drp1 S637 and p-Drp1 S616. Densitometric analysis revealed the expression of (D) total Drp1, (E) mito Drp1, (F) p-Drp1 S637 and (G) p-Drp1 S616. $\beta$-actin was used as an internal control of total protein in the cytosolic fraction. VDAC, an outer membrane mitochondrial protein, was used as an internal control of proteins in the mitochondrial fraction. Data are expressed as mean \pm standard error of the mean. Each experiment was performed in triplicate, and data are expressed as fold increase relative to the value of the control group ( $0 \mathrm{mg} / \mathrm{kg} \mathrm{LPS})$. " $\mathrm{P}<0.05 \mathrm{vs}$. control group $(0 \mathrm{mg} / \mathrm{kg} \mathrm{LPS})$; ${ }^{* *} \mathrm{P}<0.01$ vs. control group $(0 \mathrm{mg} / \mathrm{kg}$ LPS). LPS, lipopolysaccharides; Drp1, dynamin-related peptide 1; mito Drp1, mitochondrial Drp1; p-Drp1, phosphorylated Drp1; VDAC, voltage-dependent anion channel.

the TNF- $\alpha$-induced decrease in cell viability (Fig. 6E; $\mathrm{P}>0.01$ vs. TNF- $\alpha$ ). Therefore, these findings suggest that CaMK II and $\mathrm{JNK}$ are not involved in TNF- $\alpha$-induced phosphorylation of Drp1.

RhoA/ROCK pathways are involved in the phosphorylation and mitochondrial translocation of Drpl. The present investigated whether the three most prevalent members of the Rho protein family (RhoA, Cdc42 and Rac1) are involved in TNF- $\alpha$-induced Drp1 phosphorylation. Following treatment with TNF- $\alpha(20 \mathrm{ng} / \mathrm{ml})$, the expression of Rac1/Cdc42 did not exhibit a significant change; however, the expression of RhoA in H9C2 cells treated with TNF- $\alpha$ increased $~ 2.3$-fold compared with the control (Fig. 5; P<0.01 vs. control). In addition, it was demonstrated that administration of Y-27632 and fasudil ROCK inhibitors in TNF- $\alpha$ treated cells significantly attenuated the TNF- $\alpha$-induced increase in the levels of p-Drp1 Ser616 and mitochondrial Drp1 (Fig. 7; P<0.01 vs. $\mathrm{TNF}-\alpha$ ). However, when administered to non-TNF- $\alpha$ treated cells, neither Y-27632 nor fasudil demonstrated a significant effect regarding the levels of p-Drp1 Ser616 or mitochondrial Drp1 compared with the control (Fig. 7; P>0.01 vs. control). These results were confirmed by performing immunofluorescence analysis to determine the level of p-Drp1 Ser616 (Fig. 8).

TNF- $\alpha$ enhances mitochondrial fragmentation and cell death in H9C2 cells. Analysis using confocal laser microscopy demonstrated that treatment with TNF- $\alpha$ increased mitochondrial fragmentation by significant enhancement of the total number of mitochondria per cell and significant reduction of mitochondrial area (Fig. 9A-C); however, the mitochondrial 

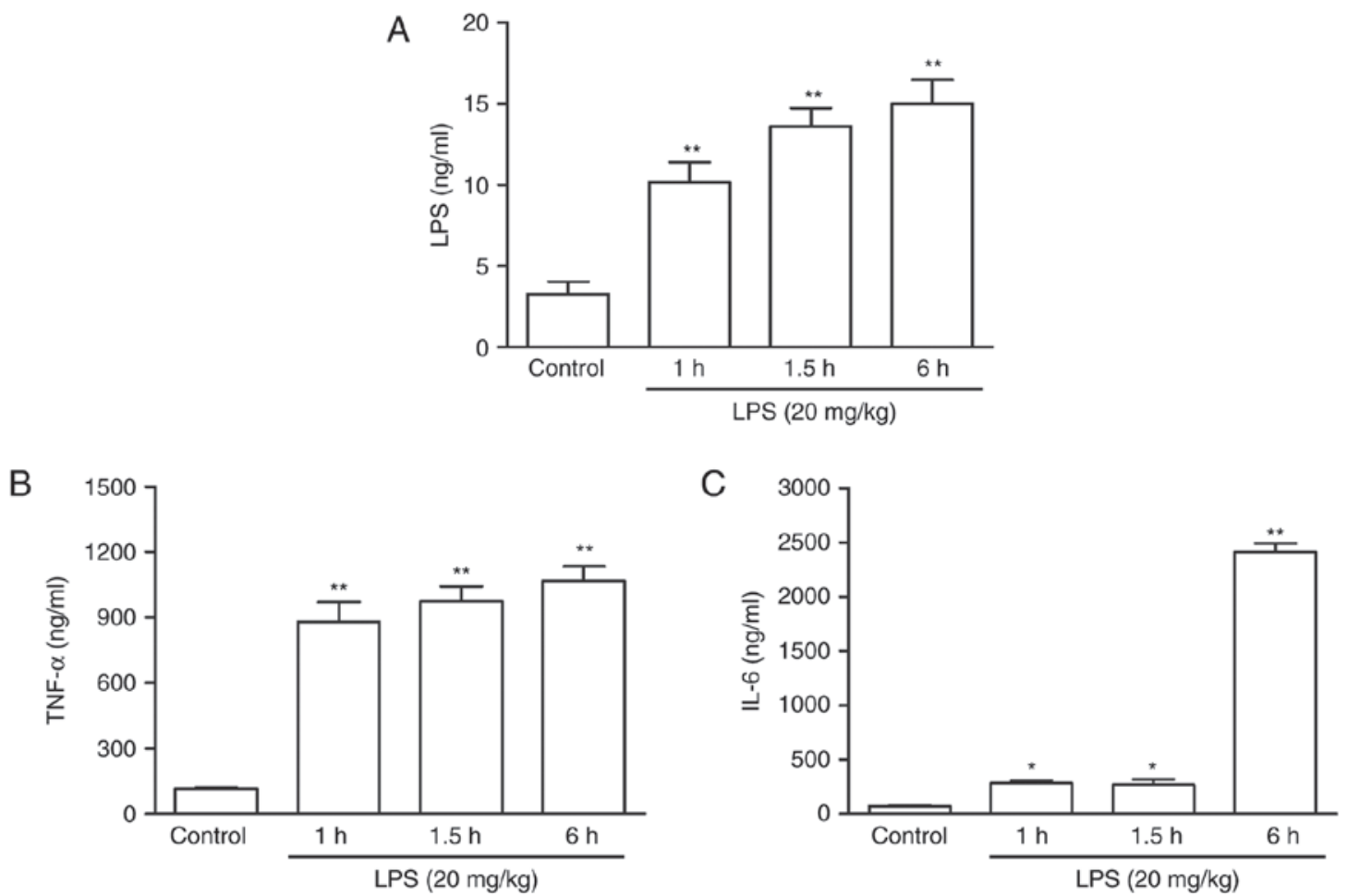

Figure 2. Concentration of serum (A) LPS, (B) TNF- $\alpha$ and (C) IL-6 in rats following injection with LPS (20 mg/kg). Data are expressed as mean \pm standard error of the mean ( $\mathrm{n}=8)$. "P<0.05 vs. control group ( $0 \mathrm{mg} / \mathrm{kg}$ LPS $) ;{ }^{* *} \mathrm{P}<0.01$ vs. control group ( $0 \mathrm{mg} / \mathrm{kg}$ LPS). LPS, lipopolysaccharides; TNF- $\alpha$, tumor necrosis factor- $\alpha$; IL-6, interleukin 6.
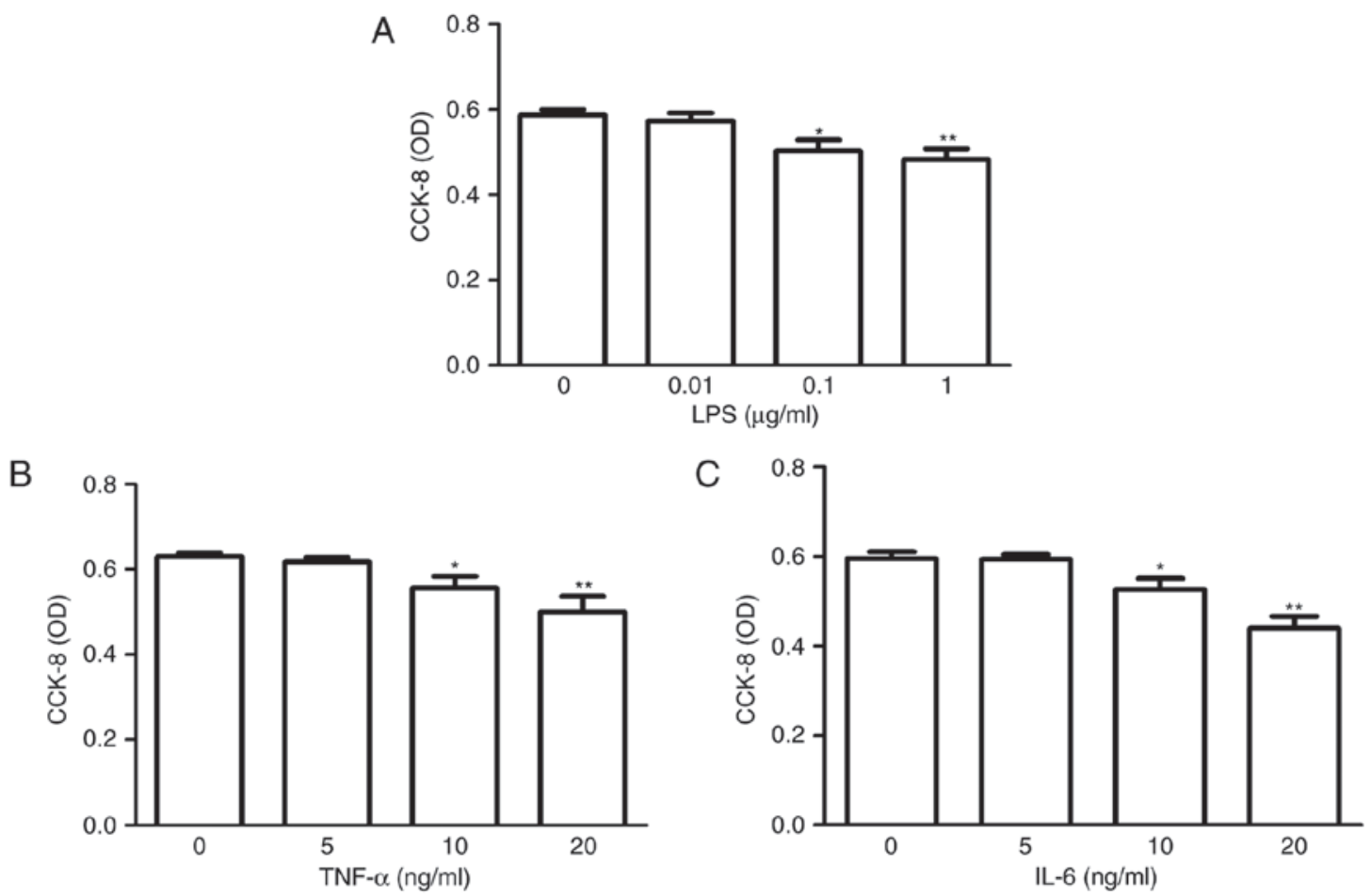

Figure 3. Determination of the viability of H9C2 cells treated with (A) LPS, (B) TNF- $\alpha$ and (C) IL-6. Data are expressed as mean \pm standard error of the mean $(\mathrm{n}=8)$. ${ }^{*} \mathrm{P}<0.05$ vs. control group; ${ }^{* *} \mathrm{P}<0.01$ vs. control group. LPS, lipopolysaccharides; TNF- $\alpha$, tumor necrosis factor- $\alpha$; IL-6, interleukin 6; CCK-8, Cell Counting Kit-8; OD, optical density.

length-width ratio did not significantly change post-treatment (Fig. 9D). Treatment with both Y-27632 or fasudil alone was revealed to significantly attenuate the increase in mitochondria per cell otherwise induced by treatment with TNF- $\alpha$ (Fig. 9A; P<0.05). Furthermore, treatment with Y-27632 alone was revealed to significantly attenuate the decrease 

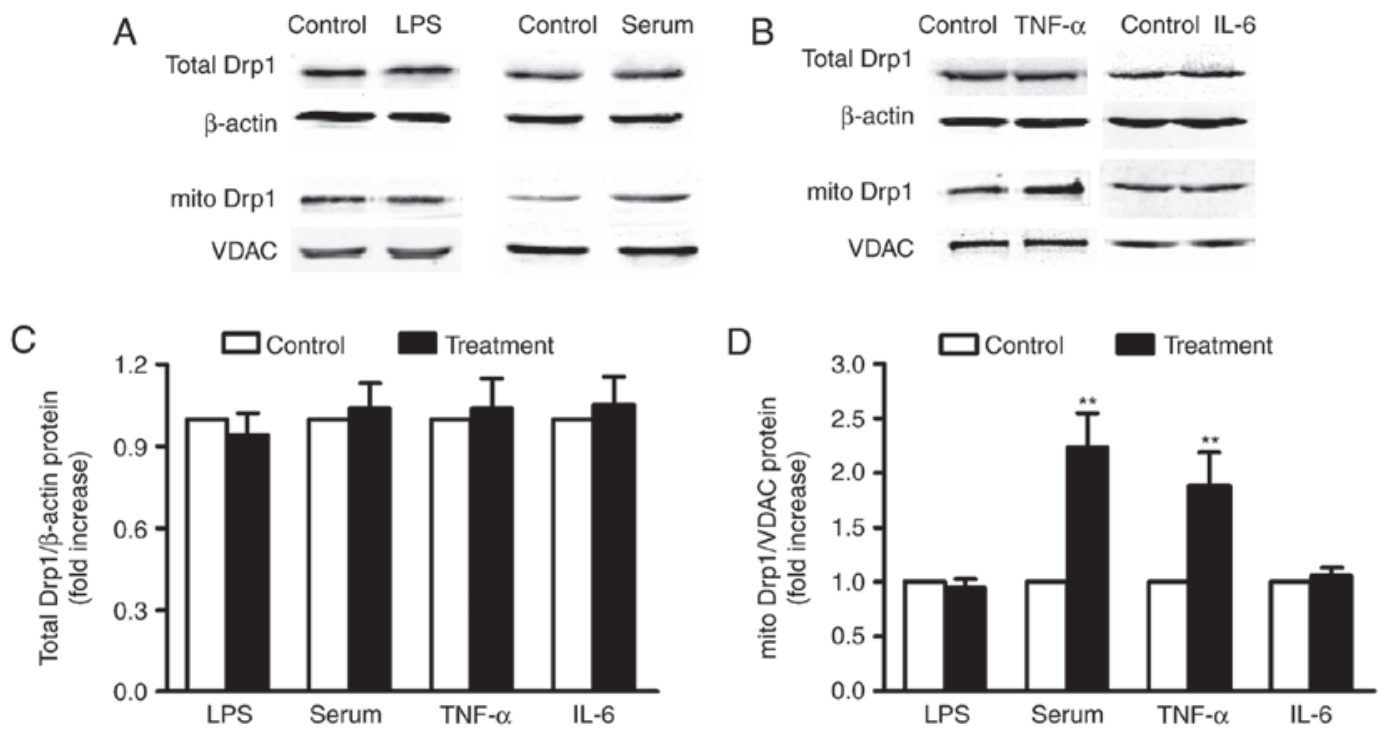

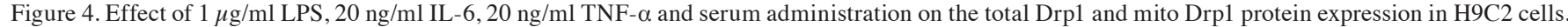
Representative western blot analyses revealing the expression levels of total Drp1 and mito Drp1 following treatment with (A) LPS and serum, and (B) TNF- $\alpha$ and IL-6. Densitometric analysis revealed the expression of (C) total Drp1 and (D) mito Drp1. Data are expressed as mean \pm standard error of the mean. Each experiment was performed in triplicate and data are expressed as fold increase relative to the value of the control group. ${ }^{* *} \mathrm{P}<0.01$ vs. control group. LPS, lipopolysaccharides; TNF- $\alpha$, tumor necrosis factor- $\alpha$; IL-6, interleukin 6; Drp1, dynamin-related peptide 1; mito Drp1, mitochondrial Drp1; VDAC, voltage-dependent anion channel.

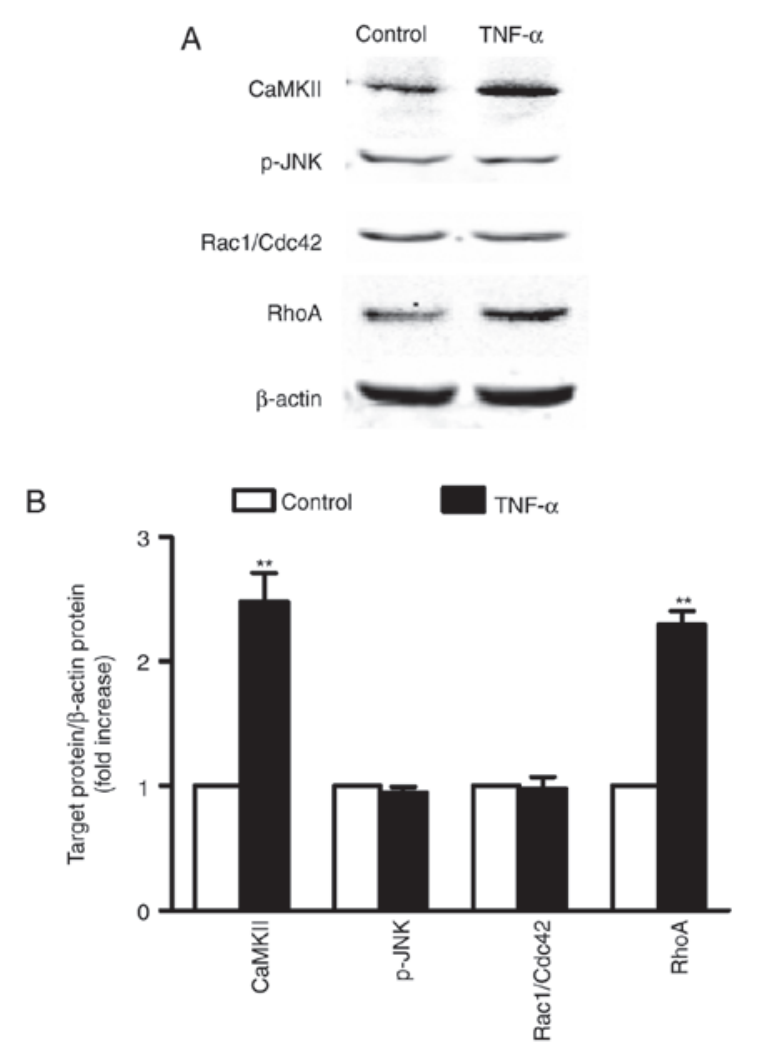

Figure 5. Effect of $20 \mathrm{ng} / \mathrm{ml}$ TNF- $\alpha$ on the expression of CaMK II, p-JNK, Rac1/Cdc42, and RhoA in H9C2 cells. (A) Representative western blot analyses revealing the expression of CaMK II, p-JNK, Rac1/Cdc42 and RhoA following treatment with TNF- $\alpha$. (B) Densitometric analysis revealed the expression of CaMK II, p-JNK, Rac1/Cdc42 and RhoA following treatment with TNF- $\alpha$. Data are expressed as mean \pm standard error of the mean. Each experiment was performed in triplicate and data are expressed as fold increase relative to the value of the control group. ${ }^{* *} \mathrm{P}<0.01$ vs. control group. TNF- $\alpha$, tumor necrosis factor- $\alpha$; CaMK II, calcium/calmodulin-dependent protein kinase type II; p-JNK, phosphorylated c-Jun N-terminal kinase; Rac1, Ras-related C3 botulinum toxin substrate 1; Cdc42, cell division control protein 42 homolog; RhoA, Ras homolog gene family member A. in mitochondrial area otherwise induced by treatment with TNF- $\alpha$ (Fig. 9B; P<0.05). Thus, administration of Y-27632 and fasudil was revealed to attenuate the TNF- $\alpha$-induced increase in mitochondrial fragmentation (Fig. 9A-D), and significantly attenuate the decrease in cell viability otherwise induced by treatment with TNF- $\alpha$ (Fig. 9E; P<0.01).

\section{Discussion}

Excessive mitochondrial fission has been previously demonstrated to be induced by inflammation stimulation in microglial cells (17), astrocytes (18) and cardiac tissue (13). The present study demonstrated that despite the total expression of Drp1 not changing significantly following treatment with LPS, the expression of mitochondrial Drp1 was significantly enhanced post-treatment. Drp1 predominantly localizes in the cytosol as a tetramer. During mitochondrial fission, Drp1 is translocated from the cytosol to the outer mitochondrial membrane and forms a ring-like structure on the surface of mitochondria, where it then induces mitochondrial scission (19).

Mitochondrial translocation of Drp1 is regulated by a number of post-translational modifications, such as phosphorylation, s-nitrosylation, ubiquitination and SUMOylation (20-23). Previous studies have demonstrated that increased phosphorylation at Drp1 Ser616 and decreased phosphorylation at Drp1 Ser637 promoted the translocation of Drp1 from the cytosol to mitochondria and induced mitochondrial fission $(24,25)$. The results of the present study demonstrated that levels of p-Drp1 Ser616 increased in the LPS-induced sepsis rat model, which is in agreement with the results obtained by Preau et al (13). However, LPS-induced system inflammation did not significantly affect the level of p-Drp1 Ser637, thus suggesting that translocation of Drp1 from the cytosol to mitochondria may occur as a result of increased phosphorylation at Drp1 Ser616. 

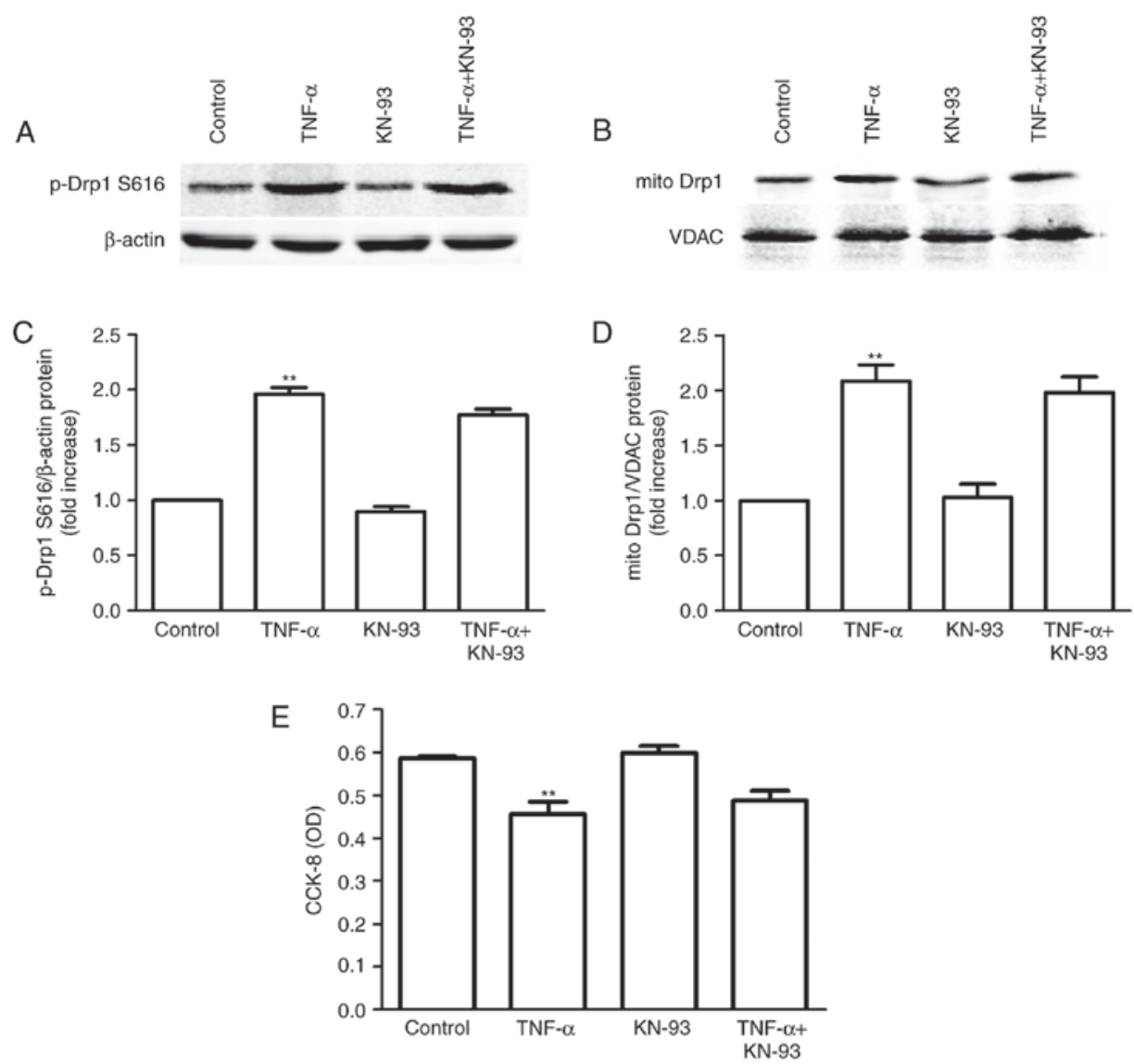

Figure 6. Effect of calcium/calmodulin-dependent protein kinase type II inhibitor $1 \mu \mathrm{M} \mathrm{KN}-93$ on the levels of p-Drp1 and mito Drp1, and the viability of H9C2 cells treated with $20 \mathrm{ng} / \mathrm{ml}$ TNF- $\alpha$. Representative western blot analyses revealing the expression of (A) p-Drp1 S616 and (B) mito Drp1 following treatment with TNF- $\alpha$, KN-93 and TNF- $\alpha+$ KN-93. Densitometric analysis revealed the expression of (C) p-Drp1 S616 protein and (D) mito Drp1 protein. Data are expressed as mean \pm standard error of the mean. Each experiment was performed in triplicate, and data are expressed as fold increase relative to the value of the control group. (E) Viability of $\mathrm{H} 9 \mathrm{C} 2$ cells. Data are mean \pm standard error of the mean. $(\mathrm{n}=8) .{ }^{* *} \mathrm{P}<0.01$ vs. control group. TNF- $\alpha$, tumor necrosis factor- $\alpha$; p-Drp1, phosphorylated dynamin-related peptide 1; mito Drp1, mitochondrial dynamin-related peptide 1; VDAC, voltage-dependent anion channel; CKK-8, Cell Counting Kit-8.
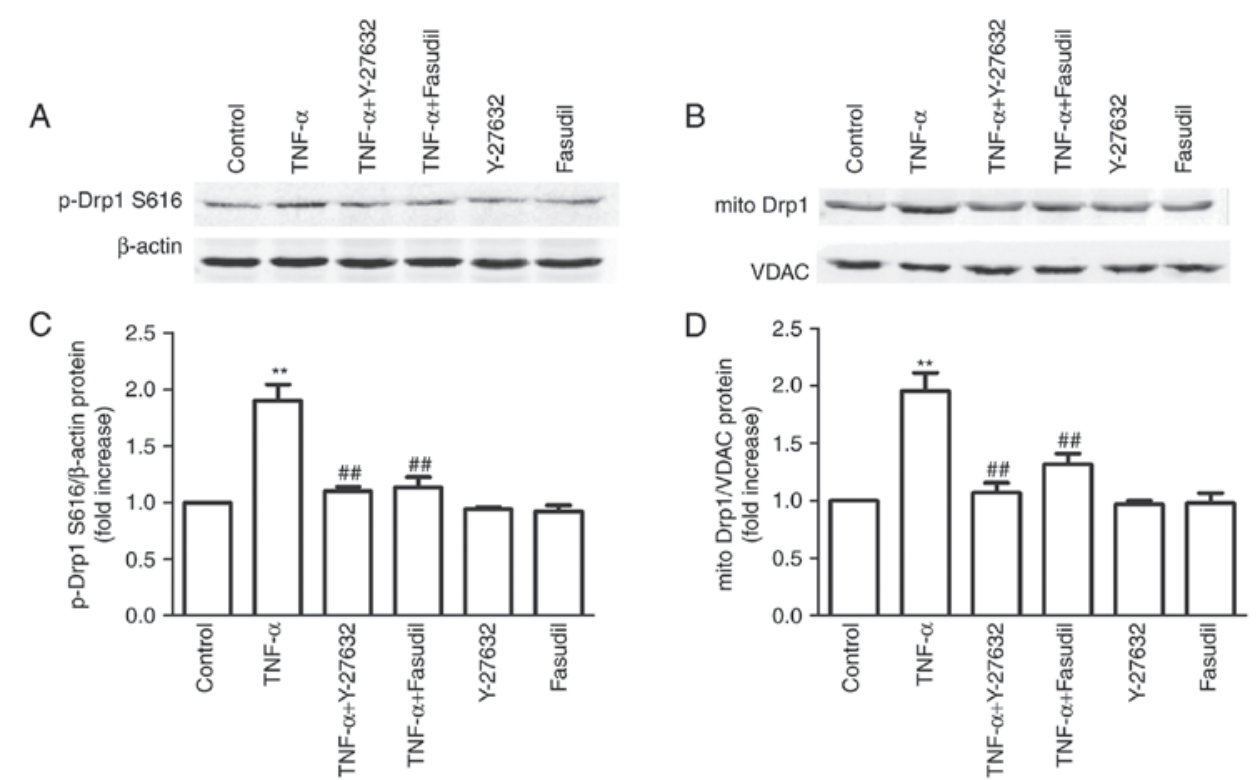

Figure 7. Effect of Rho kinase inhibitors $1 \mu \mathrm{M} \mathrm{Y-27632} \mathrm{and} 1 \mu \mathrm{M}$ fasudil on the levels of p-Drp1 and mito Drp1 in H9C2 cells treated with $20 \mathrm{ng} / \mathrm{ml} \mathrm{TNF}-\alpha$. Representative western blot analyses revealed the expression of (A) p-Drp1 S616 and (B) mito Drp1 S616 following treatment with TNF- $\alpha$, TNF- $\alpha+$ Y-27632, TNF- $\alpha+$ fasudil, Y-27632 and fasudil. Densitometric analyses revealed the expression of (C) p-Drp1 S616 and (D) mito Drp1. Data are expressed as mean \pm standard error of the mean. Each experiment was performed in triplicate, and data are expressed as fold increase relative to the value of the control group. ${ }^{* *} \mathrm{P}<0.01$ vs. control group. ${ }^{\# \#} \mathrm{P}<0.01$ vs. TNF- $\alpha$ group. p-Drp1, phosphorylated dynamin-related peptide 1 ; mito Drp1, mitochondrial dynamin-related peptide 1; VDAC, voltage-dependent anion channel; TNF- $\alpha$, tumor necrosis factor- $\alpha$. 
A
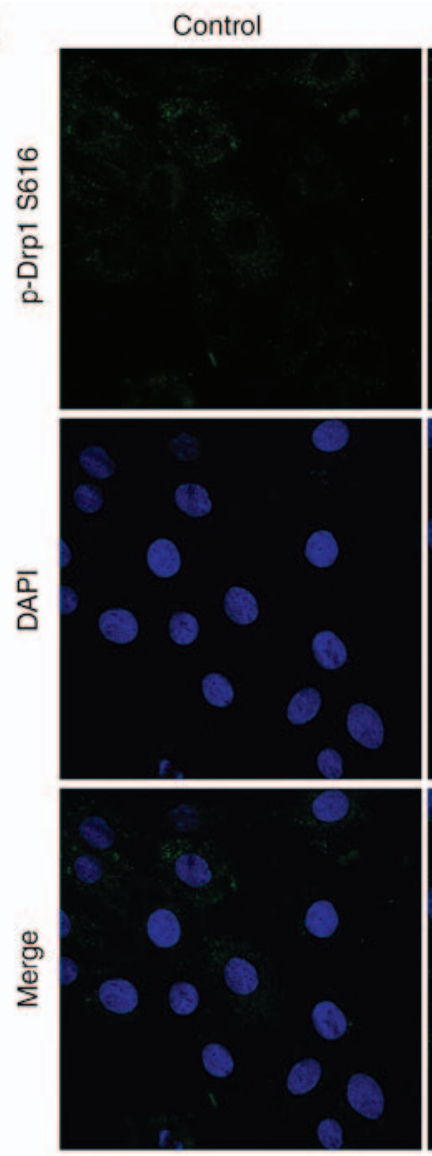

TNF- $\alpha$
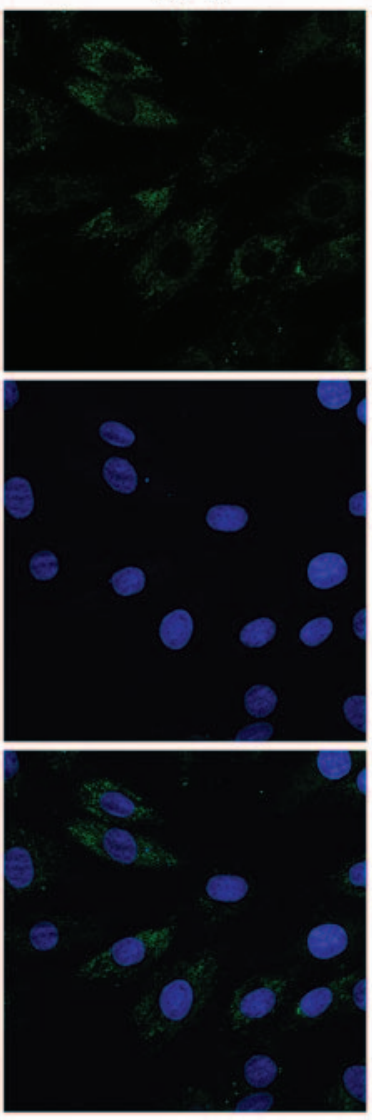

B

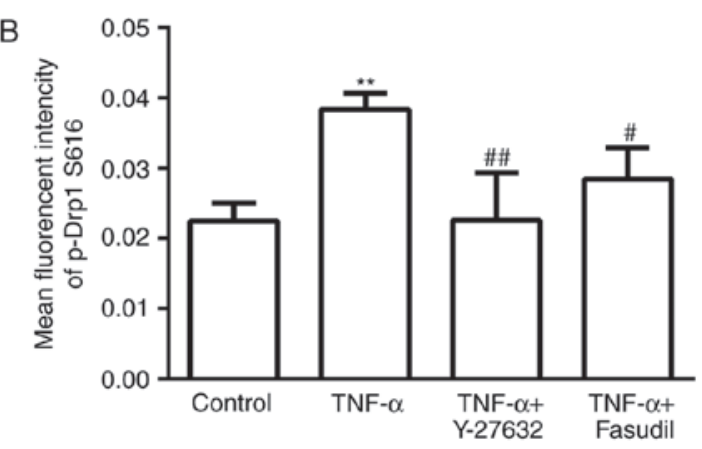

TNF- $\alpha+Y-27632$
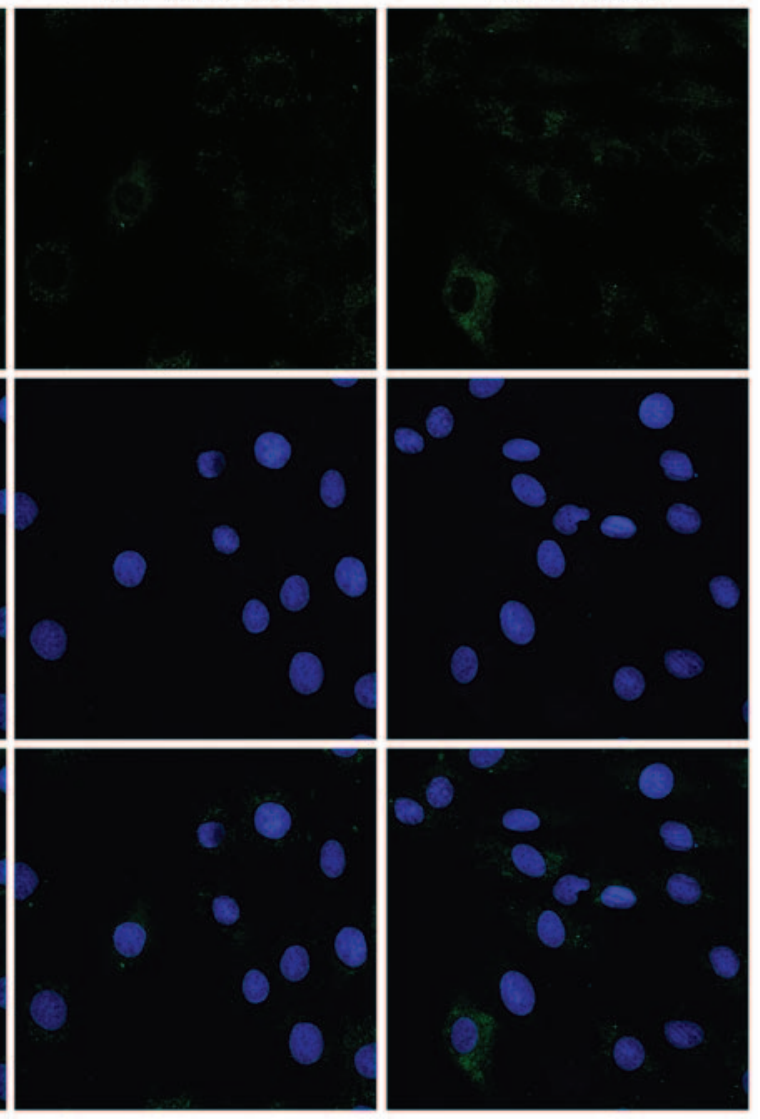

TNF- $\alpha+$ Fasudil
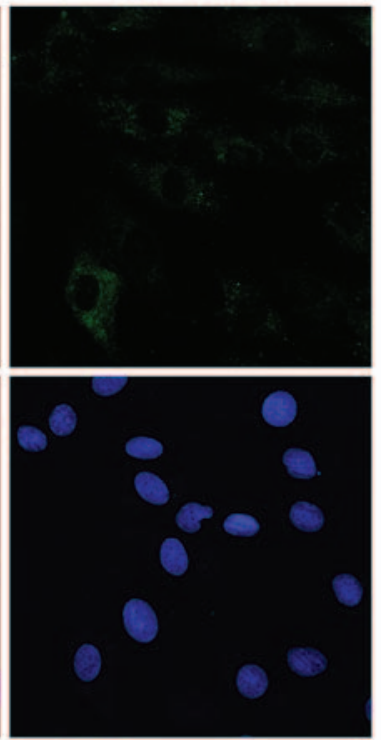
blue using DAPI. Scale bar, $20 \mu \mathrm{m}$. (B) Data analysis of the p-Drp1 S616-associated fluorescence signal. Each experiment was performed in triplicate, and data are expressed as mean \pm standard error of the mean. ${ }^{* *} \mathrm{P}<0.01$ vs. control group; ${ }^{\#} \mathrm{P}<0.05$ vs. TNF- $\alpha$ group; ${ }^{\# \#} \mathrm{P}<0.01$ vs. TNF- $\alpha$ group. TNF- $\alpha$, tumor necrosis factor- $\alpha$; p-Drp1, phosphorylated dynamin-related peptide 1; DAPI, 4',6-diamidino-2-phenylindole.

In the LPS-induced sepsis model, LPS administration was revealed to increase serum LPS concentration and increase the expression of TNF- $\alpha$ and IL-6 inflammatory cytokines. Furthermore, it was demonstrated that enhancement of TNF- $\alpha$ expression occurred at an earlier stage than that of IL-6 expression. Fernandez-Cobo et al (26) revealed that administration of LPS suppressed CX43 promoter activity as a result of the presence of cytokines, such as TNF- $\alpha$, in the serum (26). The present study investigated the effects of LPS, TNF- $\alpha$ and IL-6 administration on the phosphorylation and distribution of Drp1 in cultured $\mathrm{H} 9 \mathrm{C} 2$ cells and it was revealed that the expression of mitochondrial Drp1 was enhanced in cells treated with serum obtained from LPS injected rats, but not in cells incubated with LPS. This may be due the in vivo LPS injection rat model and its direct effect on the heart, LPS can also stimulate the immune system in order to synthesize and secrete inflammatory factors, such as TNF- $\alpha$ and IL-6, into the blood. Such inflammatory factors may be the predominant factor resulting in the induction of cardiac injury in LPS-treated rats. In in vitro cultured myocardiocytes, this effect was not observed in cells incubated with LPS in which the level of other inflammatory factors may be lower due to lack of immunological system than in vivo (26). Therefore, it may be suggested that changes in mitochondrial Drp1 expression may not be directly associated with LPS, but instead with the cytokines in the serum of the sepsis rat. The present study also demonstrated that treatment with TNF- $\alpha$, but not IL-6, increased the level of mitochondrial Drp1. Numerous studies have revealed that cellular responses to TNF- $\alpha$ and IL-6 are varied $(26,27,28)$. For example, expression of TNF- $\alpha$, but not IL-6, increases the level of cellular cholesteryl esters 


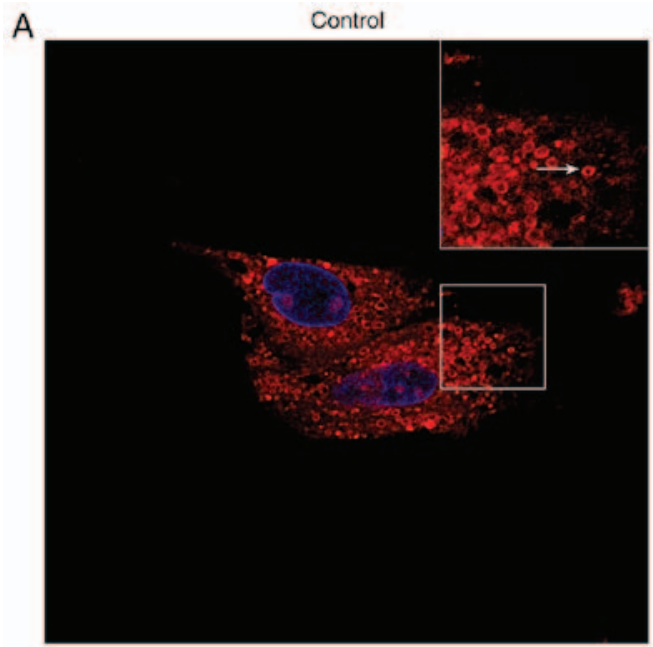

TNF- $\alpha+Y-27632$

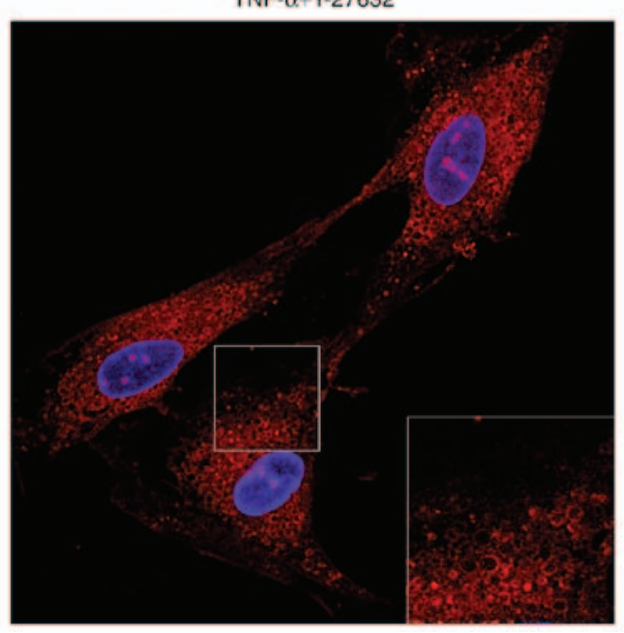

B

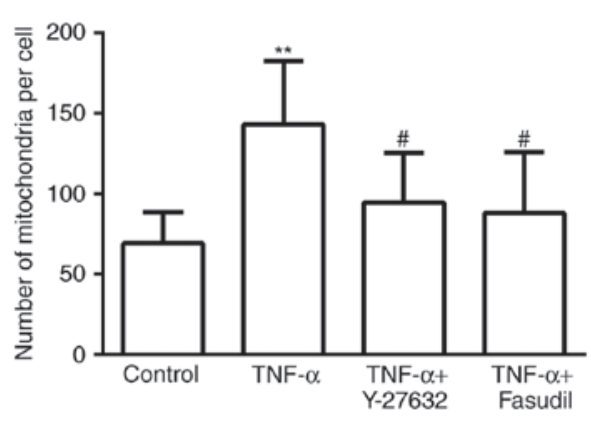

D

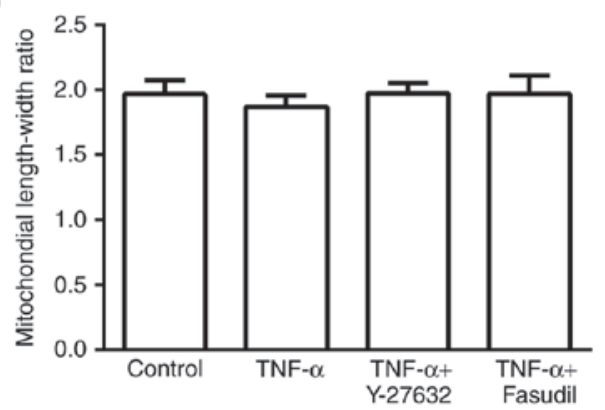

TNF $-\alpha$

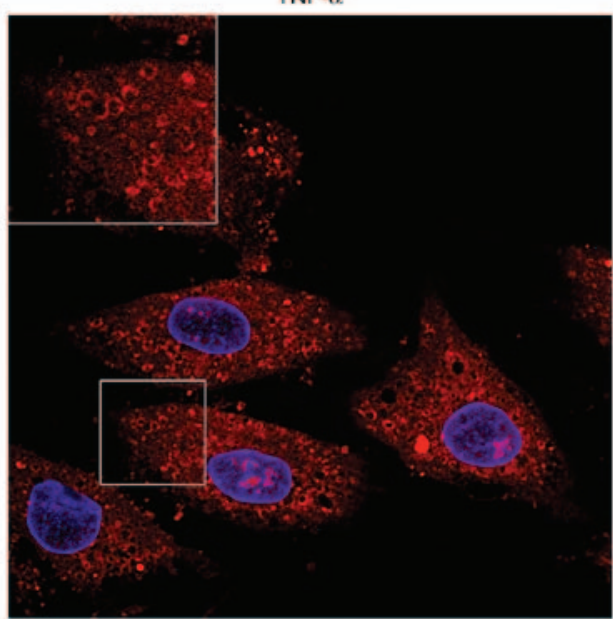

TNF- $\alpha+$ Fasudil

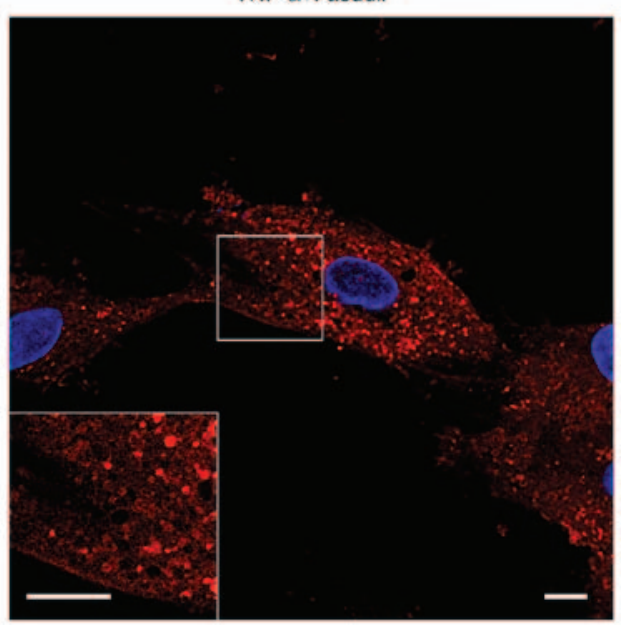

C

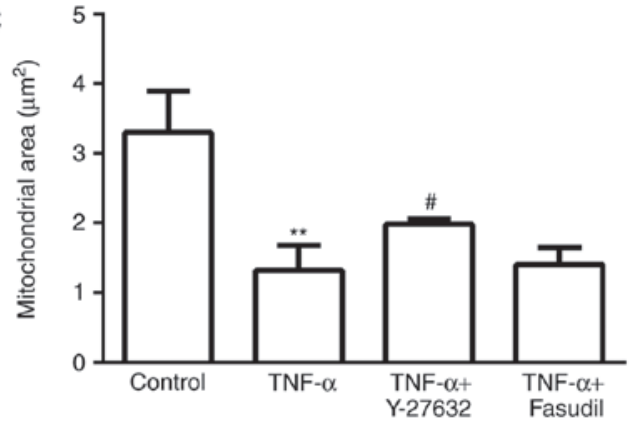

E

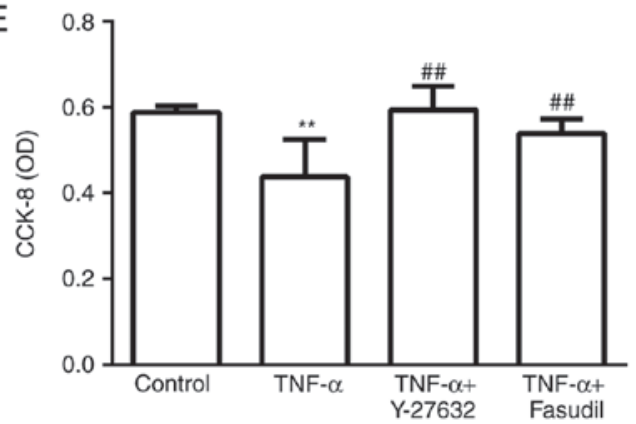

Figure 9. Effects of the administration of Rho kinase inhibitors $1 \mu \mathrm{M}$ Y-27632 and $1 \mu \mathrm{M}$ fasudil on mitochondrial morphology in $\mathrm{H} 9 \mathrm{C} 2$ cells treated with $20 \mathrm{ng} / \mathrm{ml} \mathrm{TNF}-\alpha$. (A) Representative images of the mitochondrial morphology in H9C2 cells determined using a confocal laser scanning microscope. Mitochondria were stained red using MitoTracker RedCMXRos, and nuclei were stained blue using 4',6-diamidino-2-phenylindole. Magnification, x60, Scale bar, $10 \mu \mathrm{m}$. Images within the boxed regions were further magnified and arrow indicates a single mitochondrion. Magnification, x120, scale bar, $10 \mu \mathrm{m}$. Data analyses of (B) mitochondrial quantity, (C) mitochondrial area, (D) mitochondrial length-width ratio and (E) cell viability. Data are expressed as mean \pm standard error of the mean. $(\mathrm{n}=6) .{ }^{* *} \mathrm{P}<0.01$ vs. control group; ${ }^{~} \mathrm{P}<0.05$ vs. TNF- $\alpha$ group; ${ }^{\# \#} \mathrm{P}<0.01$ vs. TNF- $\alpha$ group. TNF- $\alpha$, tumor necrosis factor- $\alpha$; CCK-8, Cell Counting Kit-8; OD, optical density. 
in monocytic cells during the development of atherosclerotic plaques (27). When both IL-6 and TNF- $\alpha$ exhibit the same negative inotropic actions in ventricular myocytes, IL-6 acts via a nitric oxide-dependent pathway, whereas TNF- $\alpha$ acts via a sphingomyelin-dependent pathway (28). During inflammation, cardiac connexin- 43 expression was decreased by TNF- $\alpha$ activity via suppression of the connexin- 43 promoter; however, cardiac connexin-43 expression was not affected by IL-6 (26). Therefore, the discrepancies between these two inflammatory cytokines may be due to their differing associated intercellular and intracellular signaling pathways. The present study also demonstrated that TNF- $\alpha$ may be an important inducer of Drp1 mitochondrial translocation during inflammatory injury of cardiomyocytes. However, the underlying mechanism of TNF- $\alpha$-induced Drp1 mitochondrial translocation remains unclear.

CaMK II regulates Drp1 phosphorylation and mitochondrial translocation $(24,29)$. CaMK II is involved in the induction of mitochondrial fission via enhancement of the level of p-Drp1 Ser616 and mitochondrial translocation of Drp1 (29). Activation of JNK has also been demonstrated to amplify the mitochondrial oxidant stress and result in Drp1 mitochondrial translocation in human hepatocytes (30). The present study revealed that treatment with TNF- $\alpha$ increased the expression of CaMK II; however, it had no significant effect on the level of p-JNK. It is of note that inhibition of CaMK II by its inhibitor KN-93 did not significantly affect the level of p-Drp1 Ser616 in TNF- $\alpha$ treated cells, nor did it attenuate the TNF- $\alpha$-induced decrease of cell viability. These findings suggested that CaMK II is not responsible for Drp1 phosphorylation and mitochondrial translocation in cardiomyocytes following treatment with TNF- $\alpha$.

The RhoA/ROCK pathway is also involved in the regulation of Drp1 phosphorylation and mitochondrial translocation $(13,31,32)$. RhoA, Cdc42 and Rac1 are the three most prevalent members of the Rho family. Abnormal activation of RhoA and its downstream effector ROCK have important roles in numerous cardiovascular disorders, such as hypertension, heart failure and atherosclerosis $(33,34)$. Recent studies have demonstrated that the RhoA/ROCK pathway is involved in the regulation of Drp1 phosphorylation and mitochondrial fission in different cell types, such as glioma cells and cardiomyocytes $(13,31,32)$. Endotoxemia engages the RhoA/ROCK pathway to impair cardiac function via alteration of the cytoskeleton, mitochondrial fission and autophagy in experimental animal models (13). In the present study, it was revealed that TNF- $\alpha$ induced the expression of RhoA, but not Cdc 42 or Rac1. Furthermore, it was also demonstrated that inhibition of ROCK activity by inhibitor administration may prevent TNF- $\alpha$-induced phosphorylation of Drp1 Ser616, mitochondrial translocation of Drp1, mitochondrial fragmentation and cell death. These findings suggested that TNF- $\alpha$ may induce cardiomyocyte death via enhancement of the level of p-Drp1 Ser616 and mitochondrial translocation in a RhoA/ROCK pathway-dependent manner.

The findings of present study suggest that TNF- $\alpha$ may be the predominant factor responsible for the phosphorylation of Drp1 S616 during sepsis. Furthermore, the results of the present study suggest that the RhoA/ROCK pathway is involved in the phosphorylation and mitochondrial translocation of Drp1, which leads to mitochondrial fragmentation.

\section{Acknowledgements}

The present study was supported by the National Natural Science Foundation of China (grant nos. 81471837 and 81272067).

\section{Competing interests}

The authors declare that they have no competing interests.

\section{References}

1. Ong SB and Hausenloy DJ: Mitochondrial morphology and cardiovascular disease. Cardiovasc Res 88: 16-29, 2010.

2. Ong SB, Kalkhoran SB, Cabrera-Fuentes HA and Hausenloy DJ: Mitochondrial fusion and fission proteins as novel therapeutic targets for treating cardiovascular disease. Eur J Pharmacol 763: 104-114, 2015.

3. Marzetti E, Csiszar A, Dutta D, Balagopal G, Calvani R and Leeuwenburgh C: Role of mitochondrial dysfunction and altered autophagy in cardiovascular aging and disease: From mechanisms to therapeutics. Am J Physiol Heart Circ Physiol 305: H459-H476, 2013.

4. Givvimani S, Pushpakumar SB, Metreveli N, Veeranki S, Kundu S and Tyagi SC: Role of mitochondrial fission and fusion in cardiomyocyte contractility. Int J Cardiol 187: 325-333, 2015.

5. Frank S, Gaume B, Bergmann-Leitner ES, Leitner WW, Robert EG, Catez F, Smith CL and Youle RJ: The role of dynamin-related protein 1, a mediator of mitochondrial fission, in apoptosis. Dev Cell 1: 515-525, 2001.

6. Ong SB, Subrayan S, Lim SY, Yellon DM, Davidson SM and Hausenloy DJ: Inhibiting mitochondrial fission protects the heart against ischemia/reperfusion injury. Circulation 121: 2012-2022, 2010.

7. Lee Y, Lee HY, Hanna RA and Gustafsson AB: Mitochondrial autophagy by Bnip3 involves Drp1-mediated mitochondrial fission and recruitment of Parkin in cardiac myocytes. Am J Physiol Heart Circ Physiol 301: H1924-H1931, 2011.

8. Li J, Li Y, Qin D, von Harsdorf R and Li P: Mitochondrial fission leads to Smac/DIABLO release quenched by ARC. Apoptosis 15: 1187-1196, 2010.

9. Borowiec A, Kontny E, Smolis-Bak E, Kowalik I, Majos E, Załucka L, Plaziński K, Maśliński W, Szwed H and Dabrowski R: Prospective assessment of cytokine IL-15 activity in patients with refractory atrial fibrillation episodes. Cytokine 74: 164-170, 2015.

10. Dunlay SM, Weston SA, Redfield MM, Killian JM and Roger VL: Tumor necrosis factor-alpha and mortality in heart failure: A community study. Circulation 118: 625-631, 2008.

11. Alturfan AA, Basar I, Emekli-Alturfan E, Ayan F, Koldas L and Emekli N: Galectin-3 and plasma cytokines in patients with acute myocardial infarction. Lab Med 45: 336-341, 2014.

12. Maeda A and Fadeel B: Mitochondria released by cells undergoing TNF- $\alpha$-induced necroptosis act as danger signals. Cell Death Dis 5: e1312, 2014.

13. Preau S, Delguste F, Yu Y, Remy-Jouet I, Richard V, Saulnier F, Boulanger E and Neviere R: Endotoxemia engages the RhoA kinase pathway to impair cardiac function by altering cytoskeleton, mitochondrial fission, and autophagy. Antioxid Redox Signal 24: 529-542, 2016.

14. Gonzalez AS, Elguero ME, Finocchietto P, Holod S, Romorini L, Miriuka SG, Peralta JG, Poderoso JJ and Carreras MC: Abnormal mitochondrial fusion-fission balance contributes to the progression of experimental sepsis. Free Radic Res 48: 769-783, 2014.

15. Hu Y, Yan JB, Zheng MZ, Song XH, Wang LL, Shen YL and Chen YY: Mitochondrial aldehyde dehydrogenase activity protects against lipopolysaccharide-induced cardiac dysfunction in rats. Mol Med Rep 11: 1509-1515, 2015.

16. Pennanen C, Parra V, López-Crisosto C, Morales PE, Del Campo A, Gutierrez T, Rivera-Mejías P, Kuzmicic J, Chiong M, Zorzano A, et al: Mitochondrial fission is required for cardiomyocyte hypertrophy mediated by a $\mathrm{Ca}^{2+}$-calcineurin signaling pathway. J Cell Sci 127: 2659-2671, 2014.

17. Park J, Choi H, Min JS, Park SJ, Kim JH, Park HJ, Kim B, Chae JI, Yim M and Lee DS: Mitochondrial dynamics modulate the expression of pro-inflammatory mediators in microglial cells. J Neurochem 127: 221-232, 2013. 
18. Motori E, Puyal J, Toni N, Ghanem A, Angeloni C, Malaguti M, Cantelli-Forti G, Berninger B, Conzelmann KK, Götz M, et al: Inflammation-induced alteration of astrocyte mitochondrial dynamics requires autophagy for mitochondrial network maintenance. Cell Metab 18: 844-859, 2013.

19. Hall AR, Burke N, Dongworth RK and Hausenloy DJ: Mitochondrial fusion and fission proteins: Novel therapeutic targets for combating cardiovascular disease. Br J Pharmacol 171: 1890-1906, 2014.

20. Rosdah AA, K Holien J, Delbridge LM, Dusting GJ and Lim SY: Mitochondrial fission -a drug target for cytoprotection or cytodestruction? Pharmacol Res Perspect 4: e00235, 2016.

21. Cho DH, Nakamura T, Fang J, Cieplak P, Godzik A, $\mathrm{Gu} \mathrm{Z}$ and Lipton SA: S-nitrosylation of Drp1 mediates beta-amyloid-related mitochondrial fission and neuronal injury. Science 324: 102-105, 2009.

22. Karbowski M, Neutzner A and Youle RJ: The mitochondrial E3 ubiquitin ligase MARCH5 is required for Drp1 dependent mitochondrial division. J Cell Biol 178: 71-84, 2007.

23. Zunino R, Schauss A, Rippstein P, Andrade-Navarro M and McBride HM: The SUMO protease SENP5 is required to maintain mitochondrial morphology and function. J Cell Sci 120: 1178-1188, 2007.

24. Godoy JA, Arrazola MS, Ordenes D, Silva-Alvarez C, Braidy N and Inestrosa NC: Wnt-5a ligand modulates mitochondrial fission-fusion in rat hippocampal neurons. J Biol Chem 289: 36179-36193, 2014.

25. Hong Z, Kutty S, Toth PT, Marsboom G, Hammel JM, Chamberlain C, Ryan JJ, Zhang HJ, Sharp WW, Morrow E, et al: Role of dynamin-related protein 1 (Drp1)-mediated mitochondrial fission in oxygen sensing and constriction of the ductus arteriosus. Circ Res 112: 802-815, 2013.
26. Fernandez-Cobo M, Gingalewski C, Drujan D and De Maio A: Downregulation of connexin 43 gene expression in rat heart during inflammation. The role of tumour necrosis factor. Cytokine 11: 216-224, 1999.

27. Zhu M, Lei L, Zhu Z, Li Q, Guo D, Xu J, Chen J, Sha H, Zhang X, Yang X, et al: Excess TNF- $\alpha$ in the blood activates monocytes with the potential to directly form cholesteryl ester-laden cells. Acta Biochim Biophys Sin 47: 899-907, 2015.

28. Sugishita K, Kinugawa K, Shimizu T, Harada K, Matsui H, Takahashi T, Serizawa T and Kohmoto O: Cellular basis for the acute inhibitory effects of IL- 6 and TNF-alpha on excitation-contraction coupling. J Mol Cell Cardiol 31: 1457-1467, 1999.

29. Xu S, Wang P, Zhang H, Gong G, Gutierrez Cortes N, Zhu W, Yoon Y, Tian R and Wang W: CaMKII induces permeability transition through Drpl phosphorylation during chronic $\beta$-AR stimulation. Nat Commun 7: 13189, 2016.

30. Ramachandran A and Jaeschke H: Mechanisms of acetaminophen hepatotoxicity and their translation to the human pathophysiology. J Clin Transl Res 3 (Suppl 1): S157-S169, 2017.

31. Gao X, Mi Y, Guo N, Hu Z, Hu F, Liu D, Gao L, Gou X and Jin W: Disrupted in schizophrenia 1 (DISC1) inhibits glioblastoma development by regulating mitochondria dynamics. Oncotarget 7: 85963-85974, 2016.

32. Yin M, Lu Q, Liu X, Wang T, Liu Y and Chen L: Silencing Drp1 inhibits glioma cells proliferation and invasion by RHOA/ROCK1 pathway. Biochem Biophys Res Commun 478: 663-668, 2016.

33. Wirth A: Rho kinase and hypertension. Biochim Biophys Acta 1802: 1276-1284, 2010.

34. Cai A, Li L and Zhou Y: Pathophysiological effects of RhoA and Rho-associated kinase on cardiovascular system. J Hypertens 34: 3-10, 2016. 